\title{
Research Article Effect of Physician Gender on Demand for Pap Tests
}

\author{
Tsui-Fang Lin ${ }^{1}$ and Jennjou Chen ${ }^{2}$ \\ ${ }^{1}$ Department of Public Finance, National Taipei University, 151 University Road, San Shia District, New Taipei City 23741, Taiwan \\ ${ }^{2}$ Department of Economics, National Chengchi University, 64 Section 2, Zhi Nan Road, Wenshan District, Taipei City 11605, Taiwan
}

Correspondence should be addressed to Tsui-Fang Lin; tflin@gm.ntpu.edu.tw

Received 2 April 2014; Revised 8 September 2014; Accepted 9 September 2014; Published 18 September 2014

Academic Editor: Stephen Jan

Copyright (C) 2014 T.-F. Lin and J. Chen. This is an open access article distributed under the Creative Commons Attribution License, which permits unrestricted use, distribution, and reproduction in any medium, provided the original work is properly cited.

\begin{abstract}
People's demand for preventive medical care is one type of investment in health. The aim of this paper is to examine women's demand for secondary prevention in Taiwan, focusing on the role a physician's gender plays in women's inclination to undergo Pap tests. Our estimation results show that regional ratio of female doctors has a positive and significant effect on utilization of Pap tests for the full sample and for women aged below 30. In addition, doctor's gender matters only in utilization of Pap tests not in other types of preventive healthcare services in Taiwan. We suggest that the government may consider liberalizing medical laws to make it legal for trained female nurses or nurse practitioners to perform Pap tests in order to encourage the utilization of Pap tests, especially in rural and mountain areas. The government may also consider subsidizing the use of cervical cancer vaccines to help females prevent cervical cancer.
\end{abstract}

\section{Introduction}

Prevention has played an increasingly important role in today's health economy as most countries face the challenge of curbing fast growing medical expenditures. Preventive medical care generally consists of primary prevention, secondary prevention, and tertiary prevention. Primary prevention including vaccination, public sanitation, and public health promotion programs reduces the occurrence or incidence of diseases. Secondary prevention referring to an array of clinical screening services for certain diseases and illnesses detects diseases earlier, treats diseases earlier, and produces better health outcomes given the occurrence of diseases. Tertiary prevention such as disease wellness and educational programs aims to avoid further medical complication. Individuals spend time and resources to purchase various types of preventive services to lower disease risk and achieve better health. Demand for preventive health services, similar to the roles which curative care and healthy lifestyles play in the health production function [1], is one type of investments in health.

Cervical cancer is a major disease leading to death of many women around the world. Pap test, one of the most reliable and effective cancer screening tests, is designed to detect cervical cancer and is recommended for women who have had sexual experience. Since the inception of National Health Insurance Programs (NHI) in 1995, free annual cervical cancer screening service is available for Taiwanese women aged over thirty. Research has shown that implementation of $\mathrm{NHI}$ has increased the uptake of Pap tests significantly [2]. In $2008,56 \%$ of women aged between 30 and 69 were reported to have undergone Pap tests in the preceding three-year period, in comparison to a mere $10 \%$ in 1994. In addition, female physicians and their relatives are found to have lower Pap test utilization rates than the general population [3].

In light of the effectiveness and cost savings of cervical cancer screening services, it is imperative to understand the determinants of utilizing Pap tests. Many factors affect women's decision to take a Pap test. A large number of prior studies have shown that age [4-9], marital status $[5,6,10]$, education $[4-6,8,10,11]$, insurance status $[4,12-14]$, public health promotion campaigns $[12,15]$, income $[9,12,16,17]$, ethnicity $[10,14]$, and characteristics of physicians $[10,16,18-$ 20] all play a vital role in the utilization of Pap tests.

To promote prevention programs and to enhance women's health require a better knowledge about determinants of inclination to take up Pap tests. In addition to social economic variables mentioned above, social cultural factors 
may also have impact on the demand for cervical cancer screening tests. For instance, a woman may hesitate or not to undertake a Pap test because the doctor is not a female due to social cultural concerns. Prior studies using either qualitative approaches or survey methods have shown that gender of the physician affects women's decision to take Pap tests. Many women report that they feel nervous and embarrassed when male physicians perform the tests $[16,20]$. The main purpose of this paper is to study the role a physician's gender plays in women's utilization of Pap tests in Taiwan. By constructing the gender ratio of obstetrics/gynecology (OB/GYN) in each county and using Pap test utilization information from a national representative health survey data, we are able to explore the impact of a doctor's gender on Pap test utilization. The contribution of this study is to quantify the magnitude of the physician gender effect which has not been explored before. A better measurement of the physician gender effect will provide valuable information to policy makers when formulating health policies. We find that regional ratio of female OB/GYNs has a positive and significant effect on utilization of Pap tests for the full sample and for women aged below 30. In addition, as expected, the gender ratio variable matters only in utilization of Pap tests but not in other types of preventive healthcare services in Taiwan. The rest of this paper is organized as follows. Section 2 describes data and empirical methods. Section 3 presents empirical results and Section 4 makes conclusion and discusses policy implications.

\section{Data and Methods}

The goal of this paper is to investigate women's demand for Pap tests in Taiwan, using the 2002 National Survey on Knowledge, Attitude, and Practice of Health Promotion (2002 NHIS; HP-KAP Survey). The 2002 NHIS, HP-KAP Survey is a national representative data set conducted by the Ministry of Health and Welfare in Taiwan. It contains rich information on various preventive healthcare services including physical examination, Pap smear, bone density test, breast checkup, blood pressure test, cholesterol test, liver function test, and proctoscopy. An array of socioeconomic variables such as age, ethnicity, education, marital status, place of residence, and family income are also detailed in the survey. In addition, we collected information on $\mathrm{OB} / \mathrm{GYN}$ for each county in 2002 and constructed the variable of the regional ratio of female doctors. After merging the county level gender ratio of OB/GYNs with the 2002 NHIS, HPKAP Survey, we are able to investigate the relationship between physician's gender and women's demand for various preventive services, including primarily Pap tests.

In this paper, the major dependent variable is a binary variable indicating whether a respondent has ever had a Pap test in the past. Due to the discrete nature of the independent variable, we employ a probit model to estimate women's demand for Pap tests. In addition, to study whether a physician's gender matters in the demand for Pap tests as women age, we estimate the demand for Pap test by different age groups. Furthermore, we examine whether the gender effect holds for other types of preventive medical care. We estimate a set of nonlinear probability models focusing on different types of preventive care such as mammography, bone density test, and a number of general physical examination items. We would expect that the county level gender ratio of OB/GYNs has smaller or insignificant effect on other types of preventive services.

To estimate demand for preventive services, we construct the following equations:

$$
\begin{gathered}
P_{i}^{*}=\alpha+\beta X_{i}+\gamma G_{i}+u_{i} \\
P_{i}=1 \quad \text { if } P_{i}^{*}>0 \\
P_{i}=0 \text { otherwise. }
\end{gathered}
$$

The above equation estimates the determinants of a wide range of preventive services including Pap tests, bone density test, breast exam, blood pressure test, cholesterol test, liver function test, and proctoscopy. $P_{i}^{*}$ is a latent variable affected by $X_{i}$ and $G_{i} . P_{i}$ is a binary variable indicating whether or not an individual uses any type of preventive services. $G_{i}$ represents the corresponding county level gender ratio of OB/GYNs. $X_{i}$ represent a vector of control variables including age, education level, employment status, marital status, health condition, income level, and ethnicity. $\alpha$ represents aconstant term and $u_{i}$ represents a residual term. $\gamma$ is the key coefficient of interest representing the physician gender effect. $\beta$ captures the effects of socioeconomic variables on demand for preventive services.

\section{Empirical Results}

Table 1 presents summary statistics of all variables used for this study. The number of female observations is 10,408 . Seven main dependent variables indicate whether or not the respondent has used different types of preventive services. For instance, nearly two-thirds of females in our sample have used Pap test at some point of time. Among females, the Pap test utilization rate is the second highest among all preventive services in our sample. Over 70 percent of females have checked their blood pressure. Less than half of the female respondents have checked their liver function and cholesterol. Less than 30 percent of females have checked their bone density and done a breast examination. Only 5 percent of females have undergone a proctoscopic examination.

It is worth noting that most physicians who practice OB/ GYN in Taiwan are males. On average, the regional ratio of female doctors is less than 20 percent. Also, average age of sampled female respondents is 48 . Half of the respondents participate in the labor force while half of them do not work. Over 70 percent of females are married in our sample. On the average, the respondents have received 8.4 years of education. 46.5 percent of respondents reported having experienced frequent menstrual pain. For the income variables, 26.7 percent of respondents belong to the lowest level, while 1.3 percent of respondents belong to the highest level. In terms of ethnicity, around 75 percent of respondents belong to Minan, 13 percent are Hakka, 8 percent are Mainlanders, and 
TABLE 1: Summary statistics.

\begin{tabular}{|c|c|c|c|c|c|}
\hline Variables & Number of observations & Mean & Standard deviation & Minimum & Maximum \\
\hline Pap test & 10,408 & 0.6533 & 0.4759 & 0 & 1 \\
\hline Bone density test & 10,408 & 0.2718 & 0.4449 & 0 & 1 \\
\hline Clinical breast exam & 10,408 & 0.2982 & 0.4575 & 0 & 1 \\
\hline Blood pressure test & 10,408 & 0.7116 & 0.4531 & 0 & 1 \\
\hline Cholesterol test & 10,408 & 0.4621 & 0.4986 & 0 & 1 \\
\hline Liver function test & 10,408 & 0.4168 & 0.4931 & 0 & 1 \\
\hline Proctoscopy & 10,408 & 0.0494 & 0.2167 & 0 & 1 \\
\hline Regional ratio of female doctors (\%) & 10,408 & 17.457 & 5.2711 & 4.17 & 25.81 \\
\hline Age & 10,408 & 48.086 & 15.831 & 25 & 97 \\
\hline $\operatorname{Age}^{2}$ & 10,408 & 2562.9 & 1669.5 & 625 & 9409 \\
\hline Years of education & 10,408 & 8.4341 & 5.0828 & 0 & 17 \\
\hline Years of education ${ }^{2}$ & 10,408 & 96.966 & 81.918 & 0 & 289 \\
\hline Employment status & 10,408 & 0.4914 & 0.4999 & 0 & 1 \\
\hline Marital status & 10,408 & 0.7080 & 0.4547 & 0 & 1 \\
\hline Frequent menstrual pain & 10,408 & 0.4650 & 0.4988 & 0 & 1 \\
\hline \multicolumn{6}{|l|}{ Income level (from low to high) } \\
\hline Level 1 & 10,408 & 0.2670 & 0.4424 & 0 & 1 \\
\hline Level 2 & 10,408 & 0.2095 & 0.4069 & 0 & 1 \\
\hline Level 3 & 10,408 & 0.1794 & 0.3837 & 0 & 1 \\
\hline Level 4 & 10,408 & 0.2261 & 0.4183 & 0 & 1 \\
\hline Level 5 & 10,408 & 0.0821 & 0.2746 & 0 & 1 \\
\hline Level 6 & 10,408 & 0.0229 & 0.1495 & 0 & 1 \\
\hline Level 7 & 10,408 & 0.0131 & 0.1136 & 0 & 1 \\
\hline \multicolumn{6}{|l|}{ Ethnic group } \\
\hline Minan & 10,408 & 0.7523 & 0.4317 & 0 & 1 \\
\hline Hakka & 10,408 & 0.1330 & 0.3396 & 0 & 1 \\
\hline Mainlander & 10,408 & 0.0819 & 0.2742 & 0 & 1 \\
\hline others & 10,408 & 0.0329 & 0.1783 & 0 & 1 \\
\hline
\end{tabular}

3 percent belong to other categories, including aboriginals and foreign immigrants.

Table 2 reports respondents' Pap test utilization rate by socioeconomic status. Nearly two-thirds of females have undergone Pap tests. Before we control for other covariates, Pap test utilization rate is the highest in an area where the regional ratio of female doctors is below 10 percent. In the area where the regional ratio of female doctors is above 20 percent, Pap smear test utilization rate is 67 percent. Among different age groups, females aged below 30 years have the lowest Pap test utilization rate while women aged between 40 and 50 have the highest utilization rate. As for the education variable, women with more years of schooling are less likely to use Pap tests. Working women compared to nonworking women have higher Pap test usages. Almost 40 percent of married women have used Pap tests, while 76 percent of nonmarried women have used Pap tests. Women with frequent menstrual pain are more likely to use Pap tests. The Pap test utilization rate for women with higher incomes is greater than for those with lower incomes. The usage of Pap test is similar for Minan, Hakka, and Mainlanders, while the usage of aboriginals and foreign immigrants is lower.

Table 3 reports the probit model estimation results. The estimated coefficient represents marginal effect of covariates on the probability of using Pap tests. We report the full sample result as well as results for different age groups. Women from different age groups might behave differently with respect to their decisions to take Pap tests. For instance, women aged over 70 receive much less benefit from cervical cancer screening and may choose not to take Pap tests regularly. It is also possible that younger women perceive lower risks of having cervical cancer and decide to delay doing Pap tests. We would also expect that doctors' gender may have different influence on women from different age groups due to cohort effect.

We find that the main variable of interest, regional ratio of female OB/GYNs, has a positive and significant effect on utilization of Pap tests for the full sample, and for women of age under 30 years. The marginal effect of physician gender on utilization of Pap tests for women aged below 30 is much greater than that for the full sample. Ten percent increases in the regional female doctor ratio will increase the probability of using Pap tests by over five percent for women aged below 30. It is important to recognize that some Taiwanese women especially younger ones may not want to take Pap tests because most OBGYNs are males. As might be expected, with increase of age, the positive effect of doctor's gender on Pap tests utilization becomes statistically insignificant. This can be seen from column 3 to column 7 in Table 3 . 
TABle 2: Pap test utilization.

\begin{tabular}{|c|c|c|c|}
\hline Variables & Number of observations & Mean & Standard deviation \\
\hline Full sample & 10,408 & 0.6533 & 0.4759 \\
\hline \multicolumn{4}{|c|}{ Regional ratio of female doctors (\%) } \\
\hline Below $10 \%$ & 1,285 & 0.6981 & 0.4593 \\
\hline Between $10 \%$ and $15 \%$ & 1,885 & 0.6106 & 0.4877 \\
\hline Between $15 \%$ and $20 \%$ & 3,801 & 0.6440 & 0.4789 \\
\hline Above $20 \%$ & 3,437 & 0.6704 & 0.4702 \\
\hline \multicolumn{4}{|l|}{ Age } \\
\hline Below 30 & 1,480 & 0.3986 & 0.4898 \\
\hline Between 30 and 40 & 2,482 & 0.7562 & 0.4294 \\
\hline Between 40 and 50 & 2,346 & 0.7856 & 0.4105 \\
\hline Between 50 and 60 & 1,554 & 0.7452 & 0.4359 \\
\hline Between 60 and 70 & 1,401 & 0.6196 & 0.4857 \\
\hline Above 70 & 1,145 & 0.4052 & 0.4912 \\
\hline \multicolumn{4}{|l|}{ Education } \\
\hline Below 6 years & 4,426 & 0.6028 & 0.4894 \\
\hline Between 6 and 9 years & 1,473 & 0.7610 & 0.4266 \\
\hline Between 9 and 12 years & 2,546 & 0.7474 & 0.4346 \\
\hline Between 12 and 16 years & 1,795 & 0.5772 & 0.4941 \\
\hline Above 16 years & 168 & 0.4286 & 0.4964 \\
\hline \multicolumn{4}{|l|}{ Employment status } \\
\hline Working & 5,114 & 0.6756 & 0.4682 \\
\hline Not working & 5,294 & 0.6318 & 0.4823 \\
\hline \multicolumn{4}{|l|}{ Marital status } \\
\hline Married & 3,039 & 0.3991 & 0.4898 \\
\hline Not married & 7,369 & 0.7582 & 0.4282 \\
\hline \multicolumn{4}{|l|}{ Frequent menstrual pain } \\
\hline Yes & 4,840 & 0.6727 & 0.4693 \\
\hline No & 5,568 & 0.6365 & 0.4811 \\
\hline \multicolumn{4}{|c|}{ Income level (from low to high) } \\
\hline Level 1 & 2,779 & 0.6589 & 0.4742 \\
\hline Level 2 & 2,180 & 0.5839 & 0.4930 \\
\hline Level 3 & 1,867 & 0.6942 & 0.4609 \\
\hline Level 4 & 2,353 & 0.6515 & 0.4766 \\
\hline Level 5 & 855 & 0.6702 & 0.4704 \\
\hline Level 6 & 238 & 0.7983 & 0.4021 \\
\hline Level 7 & 136 & 0.7647 & 0.4258 \\
\hline \multicolumn{4}{|l|}{ Ethnic group } \\
\hline Minan & 7,830 & 0.6487 & 0.4774 \\
\hline Hakka & 1,384 & 0.6893 & 0.4629 \\
\hline Mainlander & 852 & 0.6608 & 0.4737 \\
\hline Others & 342 & 0.5965 & 0.4913 \\
\hline
\end{tabular}

As for other socioeconomic variables, in the full sample, the age variable has a positive effect on the likelihood of using Pap tests. In addition, the age variable exhibits a nonlinear effect on the probability of utilizing Pap tests. Almost in all models, years of education produce a positive effect on using Pap tests after controlling for other covariates. Women with more years of schooling are more likely to take Pap tests. This may imply that more educated women know better about the benefits of prevention and use more preventive services.
It is also possible that women with more years of schooling have lower time preference rate and they choose to invest more in their own health in terms of utilizing more preventive services.

In most models, employment status produces a positive but insignificant effect on the likelihood of using Pap tests. Married women, relative to their nonmarried counterparts, are more likely to have a Pap test. Frequent menstrual pain produces a positive and significant effect on having a Pap test. 


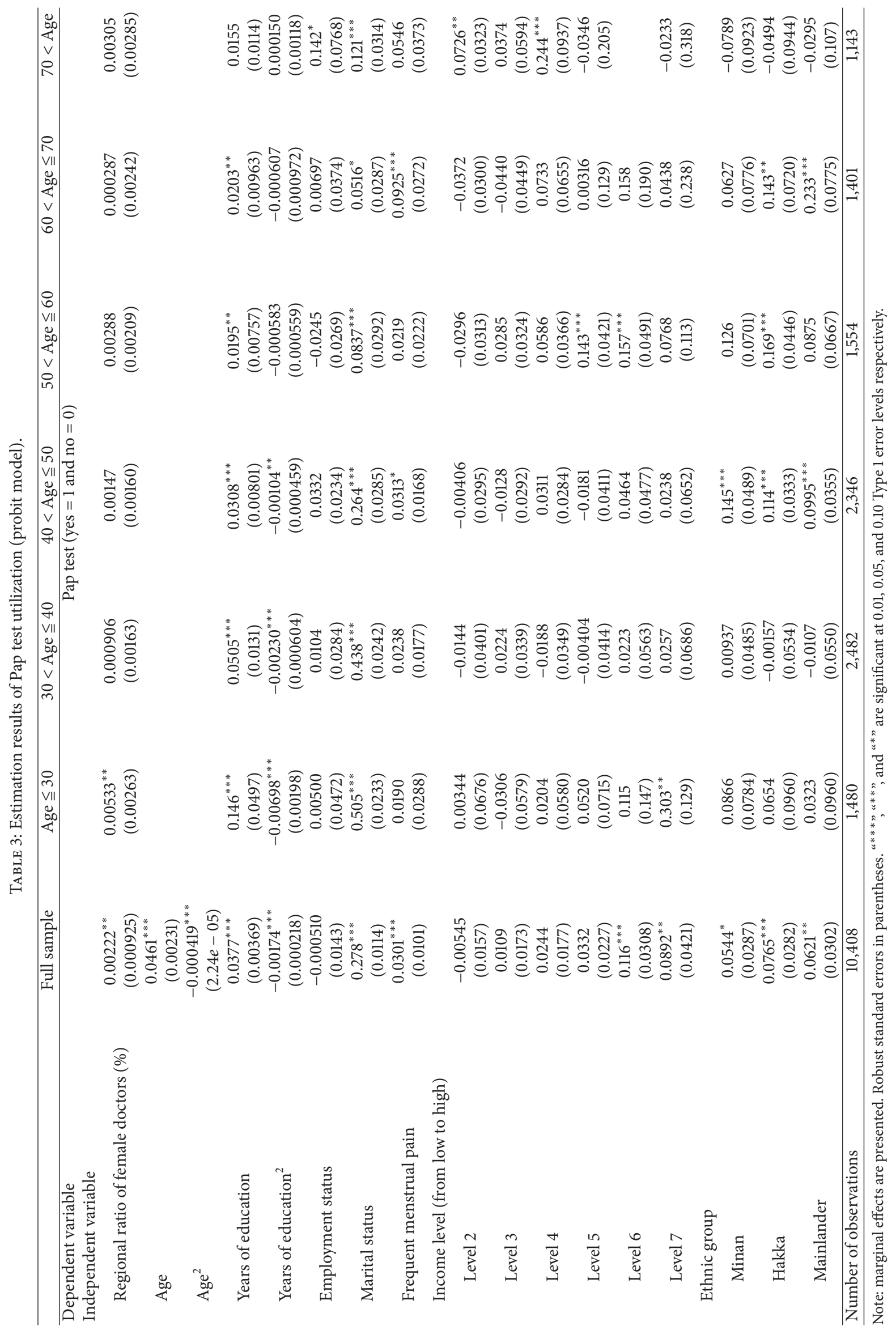




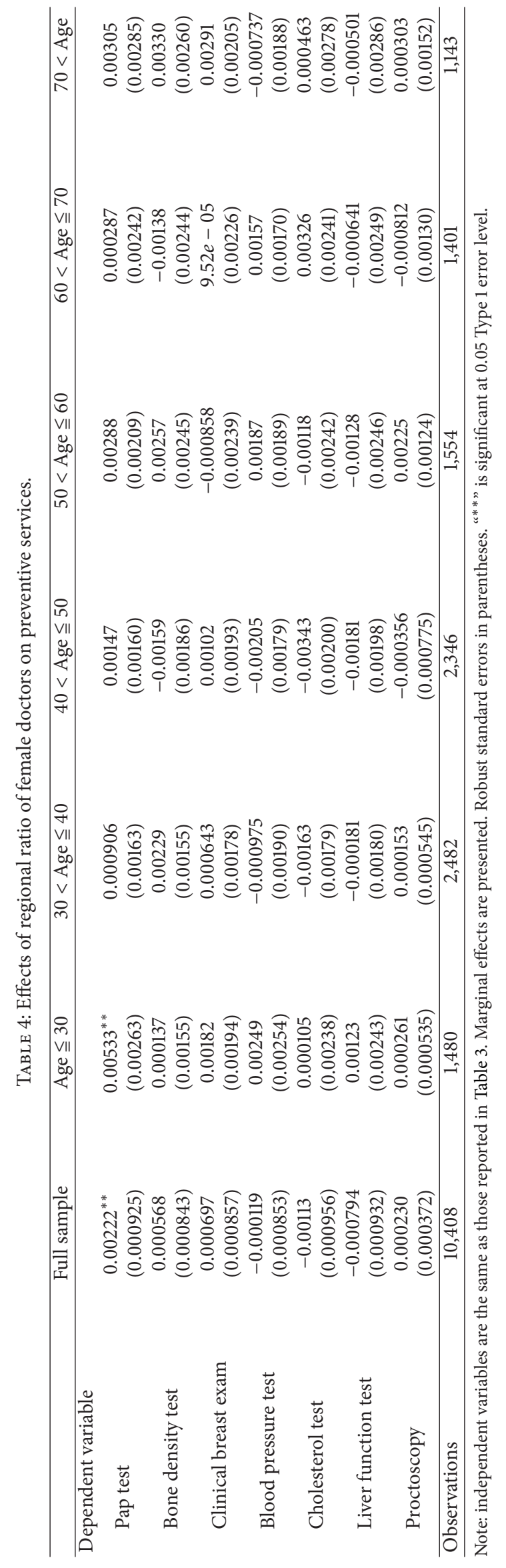


Income shows a positive effect on Pap test utilization in some models. Minan, Hakka, and Mainlanders, relative to others, are more likely to use Pap tests in case of some groups of females.

In order to investigate whether the gender ratio variable produces an effect on other types of preventive services, we estimate a variety of models. As expected, Table 4 shows that doctor's gender matters only in utilization of Pap tests but not in other types of preventive healthcare services in Taiwan. This indeed supports the argument that the gender of OB/ GYN plays an important role in the utilization of Pap tests.

\section{Conclusion}

Prevention programs have been greatly promoted and implemented to help reduce fast growing healthcare expenditures in many countries. Pap test is the most effective and reliable examination to detect cervical cancer and has been recommended for women in many parts of the world. Many factors affect women's decision to take Pap tests. This paper shows that doctors' gender, as well as age, education, marital status, ethnicity, and income play a role in the demand for Pap tests in Taiwan. The regional ratio of female OB/GYNs has produced a positive and significant effect on the probability of taking Pap tests. In particular, the physician gender effect is greater for younger women. Ten percent increases in the regional ratio of female doctors will increase the probability of using Pap tests by over five percent for women aged below 30. This implies that, similar to economic variables, social and cultural variables are important predictors in determinants of utilization of Pap tests.

In Taiwan, medical laws require that only qualified physicians perform Pap tests. OB/GYNs are mostly males; female nurses or nurse practitioners are not allowed to perform Pap tests. After controlling for other covariates, our estimation results show that gender of healthcare providers does play a significant role in the take-up of Pap tests. Hence, we suggest that the government may consider liberalizing medical laws to make it legal for trained female nurses or nurse practitioners to perform Pap tests in order to encourage the utilization of Pap tests, especially in rural and mountain areas.

In addition, vaccination of cervical cancer is not paid for or even subsidized by NHI in Taiwan. Individuals still need to pay for expensive vaccination out of their pockets. Currently it is uncommon for women to take cervical cancer vaccines against cervical cancer for themselves or for their younger daughters. In such an instance, the government may also consider subsidizing the use of cervical cancer vaccines to help females prevent cervical cancer.

\section{Conflict of Interests}

The authors declare that there is no conflict of interests regarding the publication of this paper.

\section{Acknowledgments}

Financial support during the writing of this paper provided by Taiwan's National Science Council through Grant NSC
97-2410-H305-009 is greatly appreciated. The authors also want to thank Health Promotion Administration, Ministry of Health and Welfare in Taiwan, for providing the data used for this study. Interpretations and conclusions contained herein do not represent those of Health Promotion Administration, Ministry of Health and Welfare in Taiwan.

\section{References}

[1] M. Grossman, "On the concept of health capital and the demand for health," The Journal of Political Economy, vol. 80, no. 2, pp. 223-255, 1972.

[2] Y.-J. Lin, C.-S. Chen, T.-C. Liu, and H.-C. Lin, “Taiwan's national health insurance system and the application of preventive care: the case of Pap smear testing," Public Health, vol. 122, no. 9, pp. 857-861, 2008.

[3] L.-S. Chen, N. Huang, J.-H. Tsay et al., "Screening for cervical cancer among female physicians and their relatives in Taiwana population-based comparative study," Preventive Medicine, vol. 44, no. 6, pp. 531-535, 2007.

[4] D. S. Kenkel, “The demand for preventive medical care," Applied Economics, vol. 26, pp. 313-325, 1994.

[5] P. D. Wang and R. S. Lin, "Sociodemographic factors of Pap smear screening in Taiwan," Public Health, vol. 110, no. 2, pp. 123-127, 1996.

[6] J. Cheek, J. Fuller, S. Gilchrist, A. Maddock, and A. Ballantyne, "Vietnamese women and pap smears: issues in promotion," Australian and New Zealand Journal of Public Health, vol. 23, no. 1, pp. 72-76, 1999.

[7] J. S. Mandelblatt, K. Gold, A. S. O’Malley et al., "Breast and cervix cancer screening among multiethnic women: role of age, health, and source of care," Preventive Medicine, vol. 28, no. 4, pp. 418-425, 1999.

[8] Z. H. Wu, S. A. Black, and K. S. Markides, "Prevalence and associated factors of cancer screening: why are so many older Mexican American women never screened?" Preventive Medicine, vol. 33, no. 4, pp. 268-273, 2001.

[9] P.-J. Wang, N. Huang, Y.-J. Chou, C.-H. Lee, and H.-J. Chang, "Determinants of the receipt of Pap smear screening under the National Health Insurance, a panel study during 1997-2000," Taiwan Journal of Public Health, vol. 24, no. 1, pp. 33-42, 2005.

[10] T. T. Nguyen, S. J. McPhee, T. Lam, and J. Mock, "Predictors of cervical Pap smear screening awareness, intention, and receipt among Vietnamese-American women," American Journal of Preventive Medicine, vol. 23, no. 3, pp. 207-214, 2002.

[11] R. Sabates and L. Feinstein, "The role of education in the uptake of preventative health care: the case of cervical screening in Britain," Social Science \& Medicine, vol. 62, no. 12, pp. 29983010, 2006.

[12] E. K. Adams, C. S. Florence, K. E. Thorpe, E. R. Becker, and P. J. Joski, "Preventive care: female cancer screening, 1996-2000," American Journal of Preventive Medicine, vol. 25, no. 4, pp. 301307, 2003.

[13] O. Carrasquillo and S. Pati, "The role of health insurance on Pap smear and mammography utilization by immigrants living in the United States," Preventive Medicine, vol. 39, no. 5, pp. 943950, 2004.

[14] M. A. Rodríguez, L. M. Ward, and E. J. Pérez-Stable, "Breast and cervical cancer screening: impact of health insurance status, ethnicity, and nativity of Latinas," Annals of Family Medicine, vol. 3, no. 3, pp. 235-241, 2005. 
[15] S.-I. Hou, M. E. Fernandez, E. Baumler, and G. S. Parcel, "Effectiveness of an intervention to increase Pap test screening among Chinese women in Taiwan," Journal of Community Health, vol. 27, no. 4, pp. 277-290, 2002.

[16] F. H. Lee, H. H. Wang, Y. M. Yang, and H. M. Tsai, "Barriers faced by Vietnamese immigrant women in Taiwan who do not regularly undergo cervical screenings: a qualitative study," Journal of Advanced Nursing, vol. 70, no. 1, pp. 87-96, 2014.

[17] V. Vogt, M. Siegel, and L. Sundmacher, "Examining regional variation in the use of cancer screening in Germany," Social Science \& Medicine, vol. 110, pp. 74-80, 2014.

[18] A. S. M. Abdullah, K. F. Leung, C. K. L. Leung et al., "Factors associated with the use of breast and cervical cancer screening services among Chinese women in Hong Kong," Public Health, vol. 115, no. 3, pp. 212-217, 2001.

[19] S. Eaker, H.-O. Adami, and P. Sparén, "Reasons women do not attend screening for cervical cancer: a population-based study in Sweden," Preventive Medicine, vol. 32, no. 6, pp. 482-491, 2001.

[20] R. A. Al-Naggar and Z. M. Isa, "Perception and opinion of medical students about pap smear test: a qualitative study," Asian Pacific Journal of Cancer Prevention, vol. 11, no. 2, pp. 435440, 2010. 

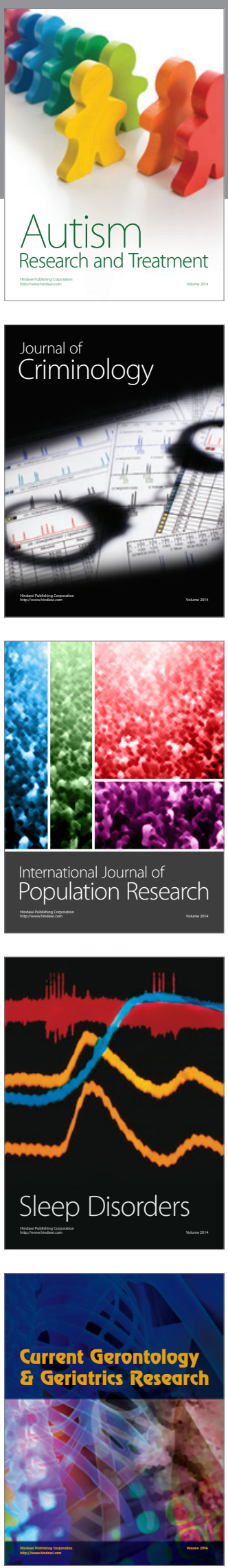
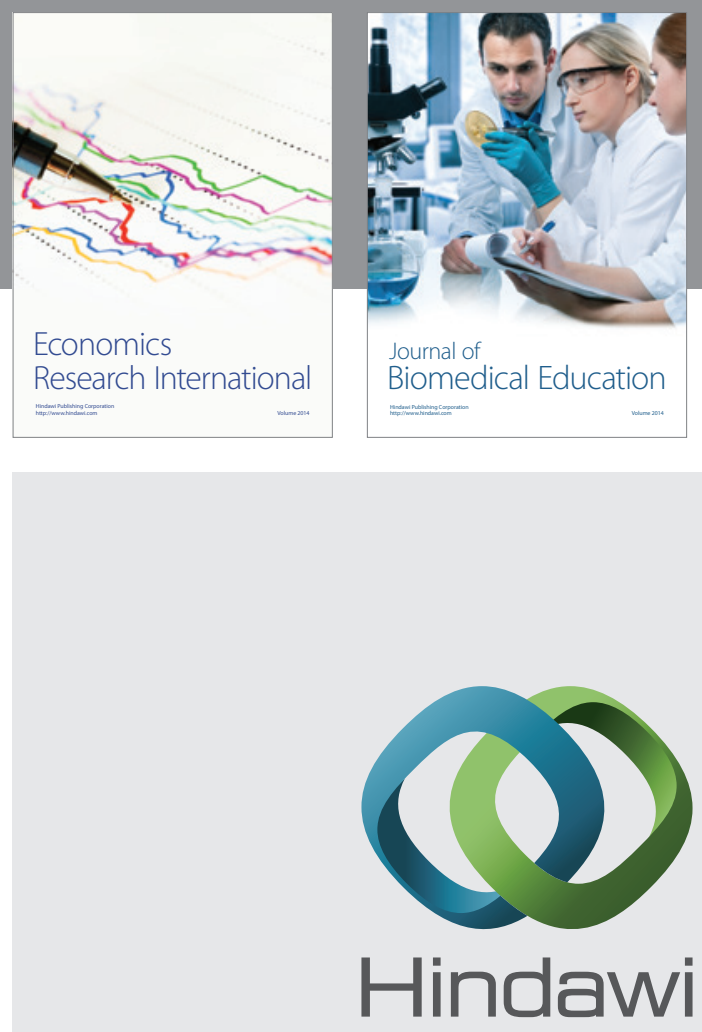

Submit your manuscripts at

http://www.hindawi.com
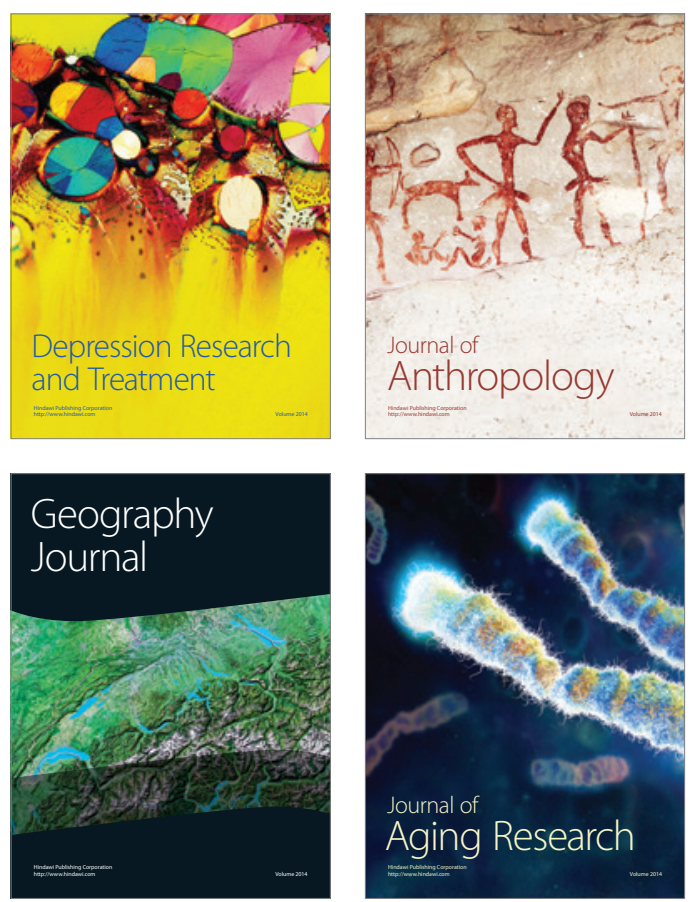
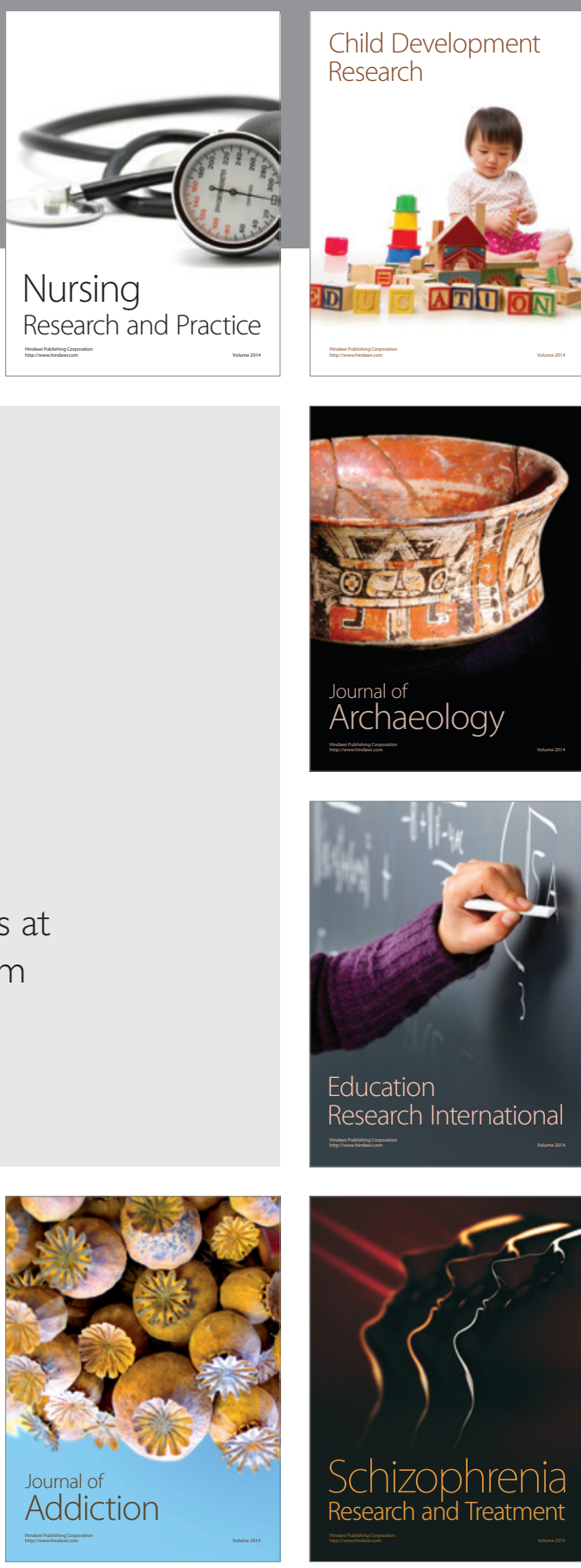

(D)
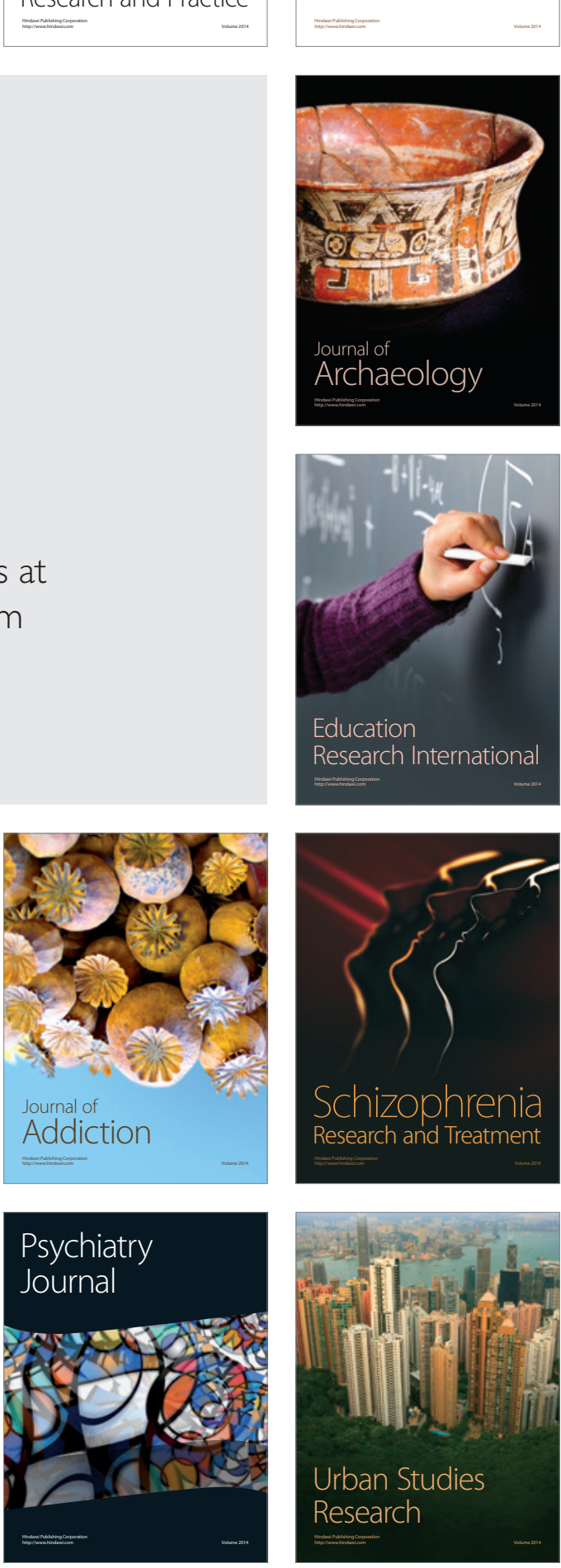